\title{
NANOSTRUCTURAL GROWTH INVESTIGATION OF ZnO NANORODS DERIVED FROM CHEMICAL BATH DEPOSITION FOR TRANSPARENT HEATER APPLICATION
}

\author{
Akhmad Herman Yuwono ${ }^{1 *}$, Lalu Suhaimi ${ }^{1}$, Nofrijon Sofyan ${ }^{1}$, Donanta Dhaneswara ${ }^{1}$, Ghiska \\ Ramahdita $^{1}$, Amalia Sholehah ${ }^{2}$, Chairul Hudaya ${ }^{3}$ \\ ${ }^{1}$ Department of Metallurgical and Materials Engineering, Faculty of Engineering, Universitas \\ Indonesia, Kampus UI Depok, Depok 16424, Indonesia \\ ${ }^{2}$ Department of Metallurgical Engineering, Faculty of Engineering, Universitas Sultan Ageng \\ Tirtayasa, Jl. Jenderal Sudirman Km 3 Cilegon, Banten 42435, Indonesia \\ ${ }^{3}$ Department of Electrical Engineering, Faculty of Engineering, Universitas Indonesia, Kampus UI \\ Depok, Depok 16424, Indonesia
}

(Received: August 2018 / Revised: September 2018 / Accepted: October 2018)

\begin{abstract}
One dimensional Zinc Oxide $(\mathrm{ZnO})$ nanostructures in the forms of nanowire, nanorod, nanotube have been attracting scientific and technology interests in the last few years. This current study investigated the effects of chemical bath deposition (CBD) synthesis parameters i.e. seeding solution concentration and growing time on the nanostructural characteristics of $\mathrm{ZnO}$ nanorods and considering their potential application for transparent heater. Seed solutions were prepared by dissolving 1:1 equimolar zinc nitrate tetrahydrate and hexamethylenetetraamine in water at $0^{\circ} \mathrm{C}$ for 1 hour. Upon the synthesis, the seeding solution concentration was varied from 0.005 , $0.025,0.05 \mathrm{M}$. The formation of thin films containing $\mathrm{ZnO}$ nanoseeds was carried out by spin coating the precursors on the conducting indium tin oxide (ITO) glass substrates, followed with annealing at $200^{\circ} \mathrm{C}$ for 5 minutes then further growing the $\mathrm{ZnO}$ nanorods at $90^{\circ} \mathrm{C}$ for 3 hours. Another variation in this work was also carried out by selecting a different route upon CBD process, i.e. with a fixed $0.05 \mathrm{M}$ seeding solution prepared from the same equimolar zinc nitrate tetrahydrate and hexamethylenetetraamine in water at $25^{\circ} \mathrm{C}$ for 1 hour, followed with the same annealing stage but continued by variation in the growing stage at $90^{\circ} \mathrm{C}$ for different times $(3,4$ and 5 hours). $\mathrm{ZnO}$ nanorods were characterized using $\mathrm{x}$-ray diffraction, field emission scanning electron microscopy and ultraviolet-visual spectroscopy. The results of these investigations demonstrated that with the increase in reaction time from 3 to 5 hours, the band gap energy, $E_{g}$ of the nanorods decreased from 3.63 to $3.13 \mathrm{eV}$, a consequence of the increase in their diameter and crystallite size from 325 to $583 \mathrm{~nm}$ and 22.68 to $34.28 \mathrm{~nm}$, respectively. The desired coverage of $\mathrm{ZnO}$ nanorods for transparent heater applications was obtained with a $0.05 \mathrm{M}$ seeding solution and 5-hour reaction time.
\end{abstract}

Keywords: Chemical bath deposition; Nanorods; Reaction time; Seeding concentration; Zinc oxide

\section{INTRODUCTION}

The development of nanostructure materials has attracted scientific and technological interests in the last few decades. This is due to the high demand for these materials in various strategic

\footnotetext{
${ }^{*}$ Corresponding author's email: ahyuwono@ui.ac.id, +62-21-7863510, Fax. +62-21-7872350

Permalink/DOI: https://doi.org/10.14716/ijtech.v9i6.2452
} 
applications owing to their unique properties at nanometer scale which are different to those of their bulk forms at the macro-and micro-scales. Therefore, one dimensional nanostructures such as nanowires, nanorods, or nanotubes have been seen as a breakthrough in the materials world. In this context, they can be expected to provide a much faster electron transfer via ballistic effect owing to their pipe-like structure.

Zinc oxide $(\mathrm{ZnO})$ is one of inorganic semiconductor oxide materials which play important role in various strategic applications including sensors (Wan et al., 2004), optoelectronic (Law et al., 2005) and piezoelectric devices (Kadota \& Miura, 2002). This can be attributed to its wide band gap energy, $E_{g}$ of $3.07 \mathrm{eV}$ and large exciton binding energy of $60 \mathrm{meV}$ at room temperature (Jin et al., 2005). $\mathrm{ZnO}$ is also well-known as one of strategic materials for piezoelectric devices due to the asymmetry in its wurtzite structure. In addition, currently $\mathrm{ZnO}$ nanostructures are being considered as potential candidate to substitute for $\mathrm{TiO}_{2}$ (titanium dioxide) in the dye sensitized solar cell (DSSC) application (Hamann et al., 2008). This is due to its electronic characteristic as direct band gap semiconductor that can be expected to be more responsive in the photon absorption process than $\mathrm{TiO}_{2}$, which is an indirect band gap semiconductor. Moreover, reducing the size of $\mathrm{ZnO}$ structures down to the nanometer scale has been hailed as a breakthrough in enhancing the performance of DSSC devices. This is based on the fact that $\mathrm{ZnO}$ nanostructures have a much higher surface-to-volume ratio compared to its bulk form, resulting in a more pronounced interaction with the dye molecules.

Vertically aligned $\mathrm{ZnO}$ nanorods have been synthesized via several established procedures including chemical vapour deposition (CVD) (Zhong et al., 2012), radio frequency sputtering (Chung et al., 2010; Shabannia \& Abu-Hassan, 2013), chemical bath deposition (CBD) (Lang et al., 2008; Gurav et al., 2011), and hydrothermal process (Pei et al., 2009). CBD is wellknown as a simple and cheap soft chemical route that runs at low temperature and provides several benefits over other methods e.g., easy control of the process condition, lower energy consumption, and higher yields (Wu et al., 2011). In our previous works we have utilized the CBD process to grow $\mathrm{ZnO}$ nanorods on conducting glass substrates and dedicated them for DSSC application (Sholehah et al., 2012; Yuwono et al., 2013; Sholehah et al., 2017). In the current study, we are exploring the potential of $\mathrm{ZnO}$ nanorods in a new and important usage, i.e. transparent heater for applications in anti-fog, anti-icing, and de-icing functions for optics and optical displays. In this context, the combination of the $\mathrm{ZnO}$ nanorods' high electrical conductivity and the optical transparency of the glass substrate on which the $\mathrm{ZnO}$ nanorods are grown is essential. To realize this, we have varied the CBD synthesis parameters-seed solution concentration and growing time - to find the most suitable precursor composition and determine the optimum conditions for the basic nanostructural characteristics and optical properties for transparent heater application.

\section{METHODS}

To form the $\mathrm{ZnO}$ nanorods, first the ITO glass substrates $(2.5 \mathrm{~cm} \times 2.5 \mathrm{~cm})$, the medium for nuclei and growth of $\mathrm{ZnO}$ nanorods, were subjected to a cleaning procedure employing sequential immersions in beakers containing deionized water, acetone and ethanol, respectively. The substrates were shaken in each beaker for 8 minutes then dried in a drying oven overnight. The seed solutions with concentrations of $0.005,0.025$, and $0.05 \mathrm{M}$ were prepared by dissolving 1:1 equimolar zinc nitrate tetrahydrate $\left(\mathrm{Zn}\left(\mathrm{NO}_{3}\right)_{2} .4 \mathrm{H}_{2} \mathrm{O}\right.$, Merck) and hexamethylene tetraamine $\left(\mathrm{C}_{6} \mathrm{H}_{12} \mathrm{~N}_{4} / \mathrm{HMTA}\right.$, Merck) in water at $0^{\circ} \mathrm{C}$ for 1 hour. The seed layers were formed on the surfaces of the cleaned and dried ITO substrates via the spin-coating technique, followed with annealing at $200^{\circ} \mathrm{C}$ for 5 minutes. The growth of the $\mathrm{ZnO}$ nanorods was subsequently completed by vertically placing the ITO substrates with the seed layer in the beaker glass 
containing the same solution and heating them in a muffle furnace at $90^{\circ} \mathrm{C}$ for 3 hours. Having completed the procedure, the samples were taken out from the beaker glass, rinsed using distilled water and dried in air at room temperature.

In this work, we also varied the synthesis route by using the same seeding solution of equimolar zinc nitrate tetrahydrate and hexamethylenetetraamine with a fixed $0.05 \mathrm{M}$ but prepared at $25^{\circ} \mathrm{C}$, instead of $0^{\circ} \mathrm{C}$. The samples were subjected to the same annealing stage and continued by variation in the growing stage at $90^{\circ} \mathrm{C}$ for different reaction times of 3,4 and 5 hours.

The crystal phase identification of $\mathrm{ZnO}$ nanorods was performed by $\mathrm{x}$-ray diffraction, XRD (Shimadzu X-Ray Diffractometer 7000; $\mathrm{Cu} \mathrm{K \alpha}$ radiation $\lambda=1.5418 \AA$ ). The average crystallite size was estimated by using Scherrer's formula on the diffraction peaks (Cullity, 1978; Suryanarayana \& Grant, 1998). The morphology of ZnO nanorods was observed via scanning electron microscopy, SEM (JEOL JSM-6510LA), whereas ultraviolet-visible (UV-Vis) absorbance spectra of the samples were recorded with a UV-Vis spectrophotometer (Shimadzu 2450). The respective $E_{g}$ were further determined by using the linear portion of absorption edges on the absorbance data by using Tauc equation (Tauc et al., 1966).

\section{RESULTS AND DISCUSSION}

\subsection{Effect of Seeding Solution Concentration}

The morphologies of the thin films of $\mathrm{ZnO}$ nanorods formed with the different seeding solution concentrations are presented in Figures 1a-f. The nanorods derived from $0.005 \mathrm{M}$ solution were still inhomogeneous, accompanied with uneven distribution in their diameters (Figures 1a and 1b). The nanorods existed as big aggregates with the average diameter of about $160 \mathrm{~nm}$. Their coverage on the substrate surface was rather poor. In the solution with the $0.025 \mathrm{M}$ concentration the nanorods characteristics were better, with more homogeneous and ordered structures covering almost the whole substrate surface (Figures 1c and 1d). The diameter distribution was quite uniform, with the averages in the range of about $205 \mathrm{~nm}$. However, vertical crystal orientation was still not completely obtained. With the $0.05 \mathrm{M}$ concentration, we obtained the most desirable $\mathrm{ZnO}$ nanorods, consisting of homogeneous and regular structures with quite uniform vertically aligned orientation over the whole surface of the substrate (Figures 1e and 1f). The average diameter of these nanorods increased up to an average of about $430 \mathrm{~nm}$. In the top-views in Figure 1, it can be clearly seen that the nanorods in each array have hexagonal cross-sections. Based on the above results, it is clear that the variation in the substrate coverage and vertical alignment of the nanorods was mainly due to the supply of $\mathrm{Zn}^{2}+$ ions to provide $\mathrm{Zn}(\mathrm{OH})_{2}$ formers to turn into $\mathrm{ZnO}$ in the growing stage. Therefore, we have selected the $0.05 \mathrm{M}$ concentration for further investigation, with varying growing times for the CBD process of 3, 4 and 5 hours; we also used a slightly higher seeding solution preparation temperature, $25^{\circ} \mathrm{C}$, for these reactions, rather than the $0^{\circ} \mathrm{C}$ of the previous procedure. This temperature was selected with the aim to provide further ripening effect for the $\mathrm{ZnO}$ nuclei upon seeding solution preparation, and thus expectedly better coverage of nanorods in the subsequent growing stage at $90^{\circ} \mathrm{C}$.

\subsection{Effect of CBD Growing Time}

Figure 2 contains the top-view SEM images of the resulting $\mathrm{ZnO}$ nanorods grown on ITO substrate glass with reaction time variations of 3,4 and 5 hours, all with a seeding solution concentration of $0.05 \mathrm{M}$. For the 3-hour reaction time (Figure 2a), most of the nanorods have grown in the vertical direction and there is good coverage on the ITO substrate. In general, the nanostructural array of $\mathrm{ZnO}$ nanorods was better than the array that resulted from the same duration time and composition in the previous reaction at $0 \mathrm{oC}$, and the average diameter of the nanorods was larger (325 vs. $160 \mathrm{~nm}$ ). By extending the reaction time from 3 to 5 hours, the 
diameter and length of nanorods increased from 325 to $583 \mathrm{~nm}$ and 0.66 to $1.98 \mu \mathrm{m}$, respectively. Table 1 presents data on the morphological characteristics of these $\mathrm{ZnO}$ nanorods, as well as the results of $E_{g}$ estimation from the optical properties measurement, which will be discussed later.
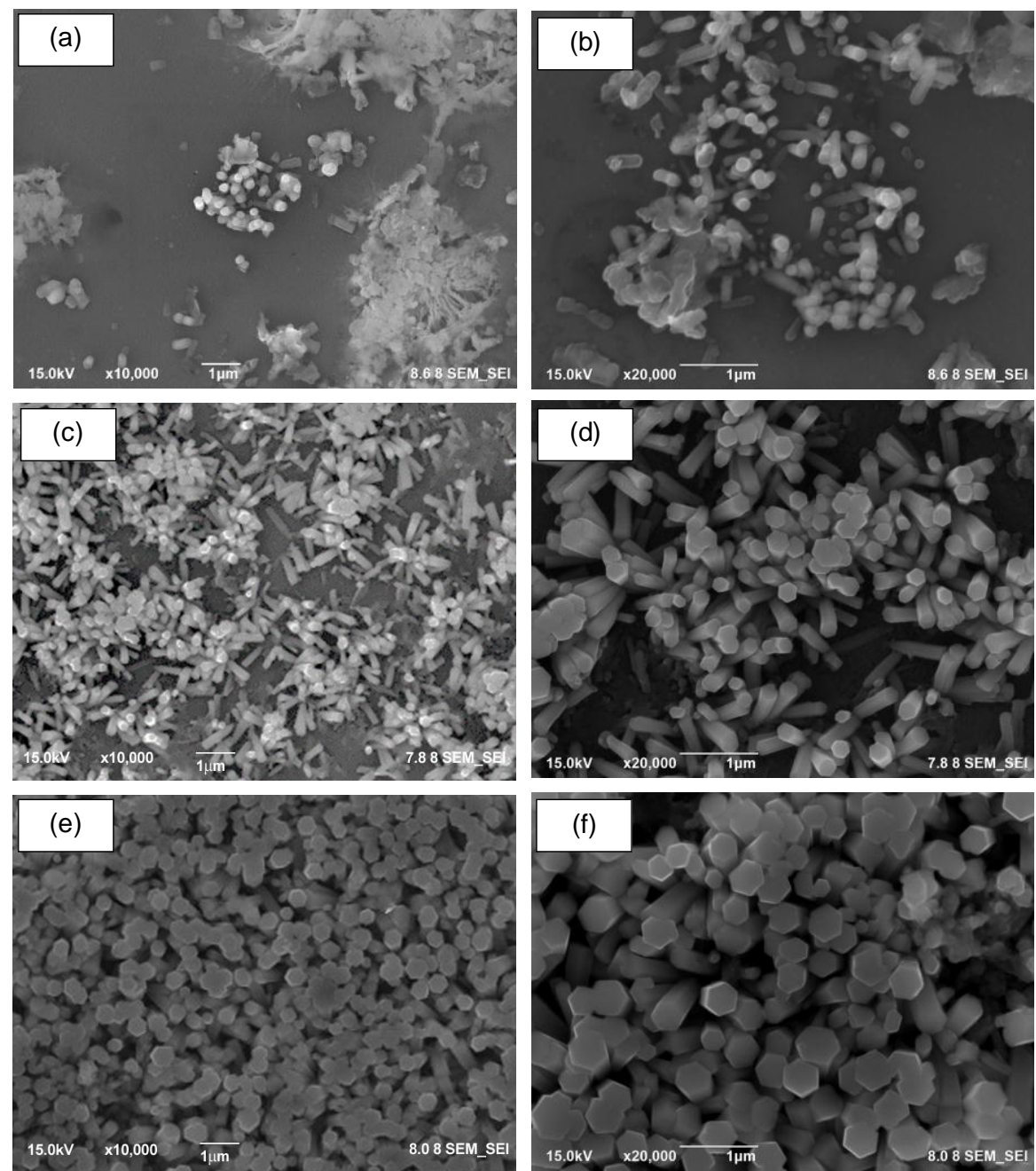

Figure 1 Top-view SEM images of $\mathrm{ZnO}$ nanorods grown via the $\mathrm{CBD}$ process at $0^{\circ} \mathrm{C}$ with seeding solution concentrations of: (a-b) 0.005; (c-d) 0.025; and (e-f) $0.05 \mathrm{M}$.
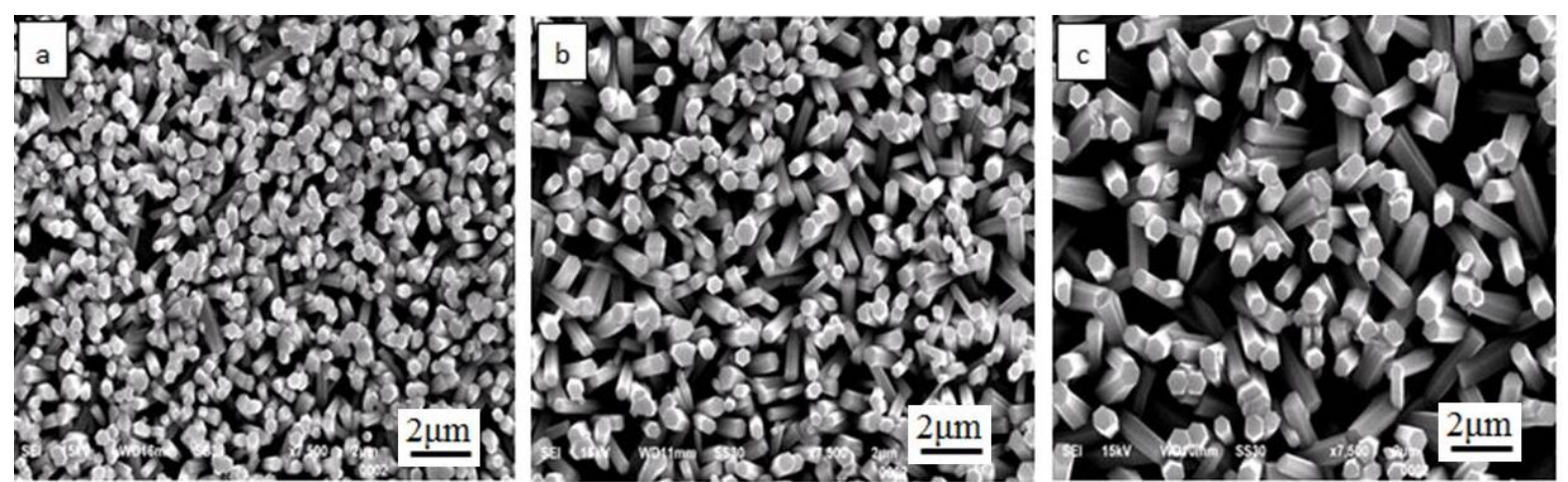

Figure 2 Top-view SEM images of $\mathrm{ZnO}$ nanorods grown via the $\mathrm{CBD}$ process at $25^{\circ} \mathrm{C}$ for: (a) 3; (b) 4; and (c) 5 hours 
As mentioned above, the average diameter of the nanorods synthesized at the higher temperature $\left(25^{\circ} \mathrm{C}\right)$ was larger than those created previously at $0^{\circ} \mathrm{C}$. Indeed, this can be attributed to the formation of more $\mathrm{ZnO}$ nuclei during the seeding stage, which then grew more extensively upon treatment with the CBD process at $90^{\circ} \mathrm{C}$ for 3 hours. The seeding solution played an important role as a ripening mechanism to then allow the nuclei to grow so substantially in the CBD step.

As presented quantitatively in Table 1 and visually in Figures $2 b$ and $2 c$, each increase in reaction time allowed for the creation of bigger nanorods, with average diameters of 444 and $583 \mathrm{~nm}$ at 4 and 5 hours, respectively. However, this growing process was adversely accompanied by a decrease in the coverage of the nanorods' array in vertical direction. This phenomenon can be associated with the fact that the higher number of reacting agents produced during longer CBD processes grew not only vertically but also horizontally. The latter was a consequence of the competition of the crystallites within the nanorods themselves. Furthermore, this horizontal growth has reduced the coverage of vertically aligned nanorods on the substrate.

Table 1 Morphology and optical properties data of $\mathrm{ZnO}$ nanorods with varying $\mathrm{CBD}$ growth times

\begin{tabular}{lccc}
\hline \multirow{2}{*}{ Morphology and optical properties } & \multicolumn{3}{c}{ Growth time (hours) } \\
\cline { 2 - 4 } & 3 & 4 & 5 \\
\hline Diameter (average, $\mathrm{nm})$ & 325 & 444 & 583 \\
Length (average, $\mu \mathrm{m})$ & 0.66 & 1.65 & 1.98 \\
Crystallite size (average, $\mathrm{nm})$ & 22.85 & 27.42 & 34.28 \\
Linear slope of absorption curve $(\mathrm{nm})$ & 365 & 375 & 420 \\
Band gap energy, $E_{g}(\mathrm{eV})$ & 3.63 & 3.55 & 3.13 \\
\hline
\end{tabular}

The XRD patterns of $\mathrm{ZnO}$ nanorods derived from the above conditions are presented in Figure 3. By comparing them with JCPDS no. 36-1451 (Wu et al., 2011), it is confirmed that all peaks belong to the polycrystalline pattern of hexagonal wurtzite $\mathrm{ZnO}$, i.e. (100), (002), (101) and (103) planes, except for the small peak found at $2 \theta$ of $35^{\circ}$ in between those of (002) and (101), which can be explained by the ITO glass.

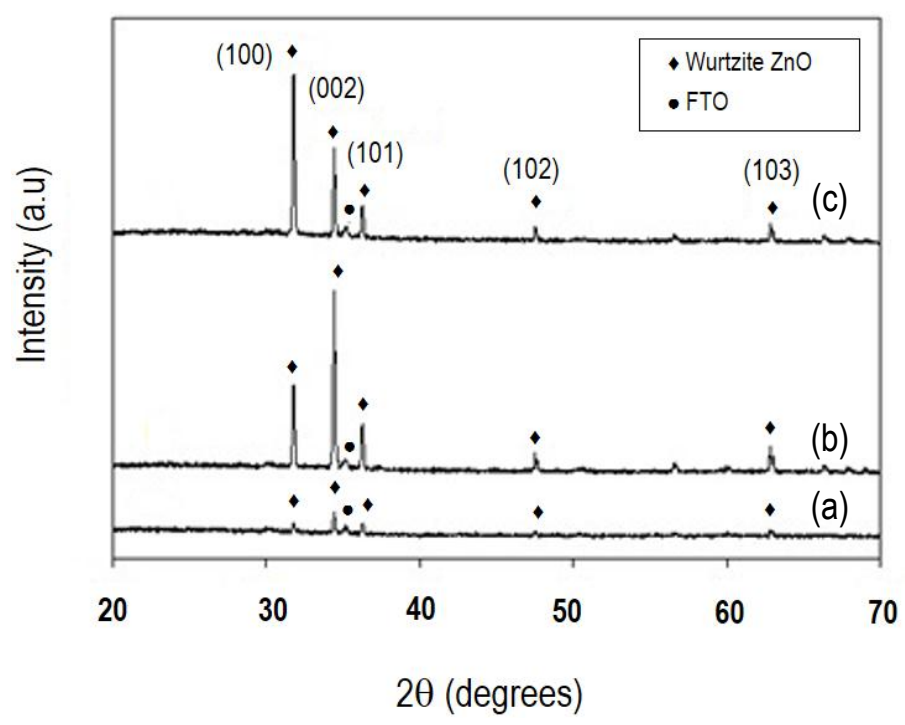

Figure 3 XRD patterns of $\mathrm{ZnO}$ nanorods grown by CBD process at $25^{\circ} \mathrm{C}$ for: (a) 3 ; (b) 4 ; and (c) 5 hours 
It is interesting to note that there was a significant increase in the (002) peak intensity when the reaction time was increased from 3 to 4 hours (Figures $3 a$ and 3b), but that the intensity was lower at the 5-hour reaction time. The same thing also occurred with the (101) peak. By contrast, the intensity of the (100) peak consistently increased with the reaction times. Such phenomena can be related to the growth nature of the $\mathrm{ZnO}$ wurtzite phase itself, as was demonstrated above via SEM analysis (Figure 2) where most of the nanorods were grown vertically along the c-axis.

A typical wurtzite $\mathrm{ZnO}$ crystal has two types of faces: the polar face of the (002) plane and the non-polar faces of the (100) and (101) planes. In the case of the polar faces, surface dipoles are thermodynamically less stable than those of the non-polar faces, so that they tend to rearrange themselves to minimize surface energy. As a consequence, the (002) plane has a faster growth rate than that produced in other directions (Wu et al., 2011). This confirms what has been nanostructurally shown in Figures $2 \mathrm{a}$ and $2 \mathrm{~b}$, where the nanorods produced at the 3 - and 4-hour durations provided the most vertically aligned structures. This is consistent with the crystallinity enhancement given by the (002) peak, as shown in Figures 3a and 3b. However, its intensity dropped down after the 5-hour reaction (Figure 3c), while the (100) peak intensity significantly increased, indicating a significant growth of crystallites along the a-axis in the form of horizontally oriented nanorods on the substrate surface. Again, this explains why the lowest nanorod coverage density was observed in the resulting sample.

Further study of the synthesized nanorods was performed via crystallite size analysis using Scherrer's formula on the diffraction data (Cullity, 1978); the average results were presented in Table 1 above. For the sake of accurate calculation, the exclusion of broadening due to the nonuniform strain and the instrumental line width in the XRD apparatus was carried out (Suryanarayana \& Grant, 1998). It is clear that the increases in the CBD growing time from 3 to 4 and finally 5 hours facilitated crystallite growth within the nanorods, with average crystallite sizes of $22.85,27.42$, and $34.28 \mathrm{~nm}$, respectively, an increase of $20 \%$ from 3 to 4 hours, and became more pronounced to about $50 \%$ with 5 hours reaction.

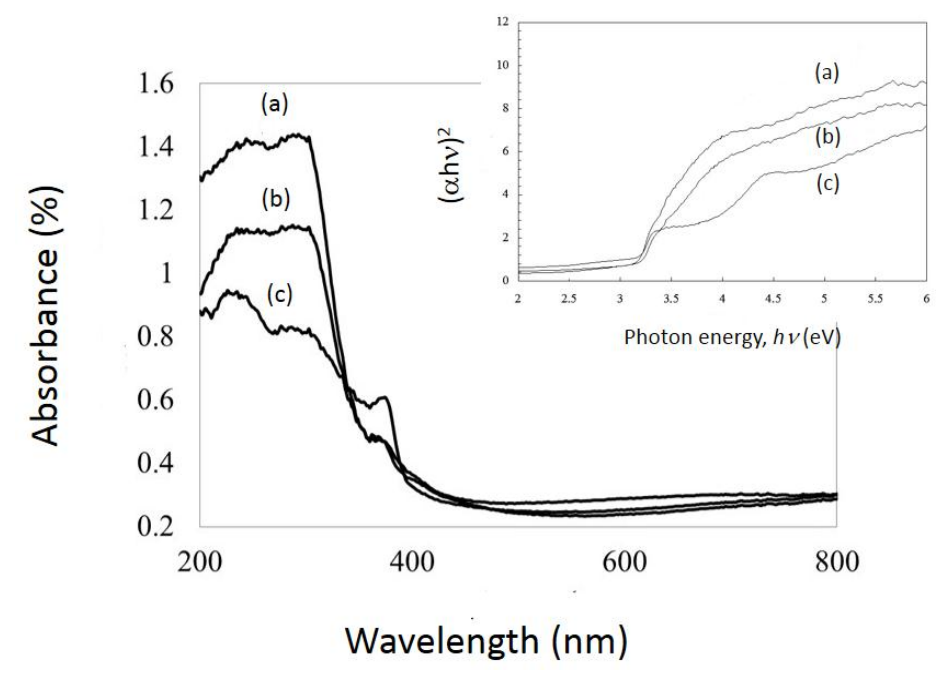

Figure 4 Absorption spectra and linear slopes of $\mathrm{ZnO}$ nanorods grown via the $\mathrm{CBD}$ process at $90^{\circ} \mathrm{C}$ for (a) 3, (b) 4, and (c) 5 hours

To confirm the nanostructural characteristics of the samples, optical measurement was carried out via UV-Vis spectroscopy. The absorbance spectra of $\mathrm{ZnO}$ nanorods are presented in Figure 4; a strong absorbance in the UV region and high transparency in the visible region were clearly observed for all samples. For obtaining quantitative data on the absorption edge, a linear slope 
of the absorption curve was taken for each spectrum (see inset, Figure 4), and Tauc's equation (Tauc et al., 1966) was used to estimate the respective $E_{g}$ of the $\mathrm{ZnO}$ nanorods. The results of both analyses were presented in Table 1. It is obvious that there was red-shifting of the $\mathrm{ZnO}$ absorption edge from 365 to 375, and finally $420 \mathrm{~nm}$ for the 3-, 4-, and 5-hour growing times, respectively. By using Tauc's equation, the calculated $E_{g}$ of the $\mathrm{ZnO}$ nanorods was found to be reduced from 3.63 to 3.55 and finally to $3.13 \mathrm{eV}$. This confirms the previous XRD analysis of the crystallite size in the nanorods. These data are also in agreement with the fact that in the nanometer scale the crystallite size of semiconductor materials strongly affects the $E_{g}$. Smaller $E_{g}$ is obtained with bigger nanocrystallite sizes and thus higher crystallinity, as observed in our previous studies on conventionally annealed and post-hydrothermally treated $\mathrm{TiO}_{2}$ nanoparticles derived from the sol-gel process (Yuwono et al., 2004), $\mathrm{TiO}_{2}$ nanotubes (Yuwono et al., 2011a; Yuwono et al., 2011b), ZnO nanoparticles (Yuwono et al., 2012b), and ZnO nanorods (Sholehah et al., 2013).

In terms of electronic properties, the smaller $E_{g}$ facilitates the electron excitation from the valence band to the higher energy state of the conduction band. This demonstrates the potential of the resulting $\mathrm{ZnO}$ nanorods for transparent heater applications. However, a preliminary trial of the samples' possible application to that function could not provide the desired confirmation. Further investigation with a four-point probe test resulted in a rather high electrical resistance from the samples. It is highly possible that the thickness of $\mathrm{ZnO}$ nanorod layers on the ITO glass substrate was not yet sufficient to allow the film to function properly in the electrical current-heating conversion. Further optimization of the CBD process is in progress to obtain sufficient thicknesses of $\mathrm{ZnO}$ nanorod layers for confirming that the electrical conductivity requirement necessary can be obtained while still maintaining suitable optical transparency.

\section{CONCLUSION}

In this study $\mathrm{ZnO}$ nanorods grown on glass substrates were successfully synthesized via CBD technique involving seeding and growing stages. It has been found that a seeding solution $(0.05$ $\mathrm{M})$ prepared at $25^{\circ} \mathrm{C}$ can provide more homogeneous coverage of $\mathrm{ZnO}$ nanorods on the substrate surface with a larger average nanorod diameter, in comparison to previous reactions at $0^{\circ} \mathrm{C}$. This resulted from the ripening mechanism in the seeding stage, which allowed the nuclei to grow more in the subsequent CBD process. Varying CBD growing time from 3 to 5 hours produced nanorods with average crystallite sizes and $E_{\mathrm{g} S}$ of 22.85 to $32.48 \mathrm{~nm}$ and 3.63 to 3.13 $\mathrm{eV}$. Considering their nanostructural charateristics and optical properties, the resulting $\mathrm{ZnO}$ nanorod samples are promising for transparent heater applications. However, further optimization is still necessary to achieve the desired combination of high transparency and electrical conductivity.

\section{ACKNOWLEDGEMENT}

This project was financially supported by the Directorate of Research and Community Services of Universitas Indonesia through the PITTA Research Grant of Universitas Indonesia, Year 2018, contract number 2370/UN2.R3.1/HKP.05.00/2018.

\section{REFERENCES}

Chung, J., Lee, J., Lim, S., 2010. Annealing Effects of ZnO Nanorods on Dye-sensitized Solar Cell Efficiency. Physica B: Condensed Matter, Volume 405(11), pp. 2593-2598

Cullity, B.D., 1978., Elements of X-ray Diffraction, Addison-Wesley Publishing Company, Reading-Massachusetts, USA 
Gurav, K., Patil, U., Pawar, S., Kim, J., Lokhande, C., 2011. Controlled Crystallite Orientation in $\mathrm{ZnO}$ Nanorods Prepared by Chemical Bath Deposition: Effect of $\mathrm{H}_{2} \mathrm{O}_{2}$. Journal of Alloys and Compounds, Volume 509(29), pp. 7723-7728

Hamann, T.W., Martinson, A.B., Elam, J.W., Pellin, M.J., Hupp, J.T., 2008. Aerogel Templated ZnO Dye-sensitized Solar Cells. Advanced Materials, Volume 20(8), pp. 1560-1564

Jin, C., Tiwari, A., Narayan, R.J., 2005. Ultraviolet-Illumination-Enhanced Photoluminescence Effect in Zinc Oxide Thin Films. Journal of Applied Physics, Volume 98(8), pp. 083707083707-7

Kadota, M., Miura, T., 2002. Shear Bulk Wave Transducer Made of (1120)-Plane Epitaxial $\mathrm{ZnO}$ Film on R-Sapphire. Japanese Journal of Applied Physics, Volume 41(2002), pp. 3281-3284

Lang, J., Yang, J., Li, C., Yang, L., Han, Q., Zhang, Y., Wang, D., Gao, M., Liu, X., 2008. Synthesis and Optical Properties of ZnO Nanorods. Crystal Research and Technology, Volume 43(12), pp. 1314-1317

Law, M., Greene, L.E., Johson, J.C., Saykally, R., Yang, P., 2005. Nanowire Dye-sensitized Solar Cells. Nature Materials, Volume 4, pp. 455-459

Pei, L., Wang, J., Tan, W., Yu, H., Fan, C., Chen, J., Zhang, Q.-F., 2009. A Convenient Synthesis Route to the Zinc Metagermanate Nanorods. Current Nanoscience, Volume 5(4), pp. $470-473$

Shabannia, R., Abu-Hassan, H., 2013. Vertically Aligned ZnO Nanorods Synthesized using Chemical Bath Deposition Method on Seed-Layer ZnO/Polyethylene Naphthalate (PEN) Substrates. Materials Letters, Volume 90, pp. 156-158

Sholehah, A., Yuwono, A.H., Permana, S., Saleh, N., Waluyo, M., 2012. Synthesis and Characterization of Zinc Oxide Tetrapods from Zinc Galvanization Dross. Advanced Materials Research, pp. 1407-1410

Sholehah, A., Yuwono, A.H., Rimbani, C.R., 2013. Controlling the Crystallite Size of Zinc Oxide Nanorods via Chemical Bath Deposition and Post-hydrothermal Treatment. Materials Science Forum, Volume 737, pp. 28-32

Sholehah, A., Yuwono, A.H., Sofyan, N., Hudaya, C., Amal, M.I., 2017. Effect of Posthydrothermal Treatments on the Physical Properties of $\mathrm{ZnO}$ Layer Derived from Chemical Bath Deposition. International Journal of Technology, Volume 8(4), pp. 651-661

Suryanarayana, C., Grant, N., 1998. A Practical Approach. Plenum Press. New York

Tauc, J., Grigorovici, R., Vancu, A., 1966. Optical Properties and Electronic Structure of Amorphous Germanium. Physica Status Solidi (b), Volume 15(2), pp. 627-637

Wan, Q., Li, Q., Chen, Y., Wang, T.-H., He, X., Li, J., Lin, C., 2004. Fabrication and Ethanol Sensing Characteristics of $\mathrm{ZnO}$ Nanowire Gas Sensors. Applied Physics Letters, Volume 84(18), pp. 3654-3656

Wu, X., Chen, H., Gong, L., Qu, F., Zheng, Y., 2011. Low Temperature Growth and Properties of ZnO Nanorod Arrays. Advances in Natural Sciences: Nanoscience and Nanotechnology, Volume 2(3), pp. 1-4

Yuwono, A.H., Liu, B., Xue, J., Wang, J., Elim, H.I., Ji, W., Li, Y., White, T.J., 2004. Controlling the Crystallinity and Nonlinear Optical Properties of Transparent $\mathrm{TiO}_{2}-\mathrm{PMMA}$ Nanohybrids. Journal of Materials Chemistry, Volume 14(20), pp. 2978-2987

Yuwono, A.H., Ferdiansyah, A., Sofyan, N., Kartini, I., Pujianto, T.H., 2011a. $\mathrm{TiO}_{2}$ Nanotubes of Enhanced Nanocrystallinity and Well-preserved Nanostructure by Pre-annealing and Post-hydrothermal Treatments. AIP Conference Proceedings, pp. 159-162

Yuwono, A.H., Sofyan, N., Kartini, I., Ferdiansyah, A., Pujianto, T.H., $2011 b$. Nanocrystallinity Enhancement of $\mathrm{TiO}_{2}$ Nanotubes by Post-hydrothermal Treatment. Advanced Materials Research, Volume 277, pp. 90-99 
Yuwono, A.H., Sofyan, N., Harjanto, S., Daneswara, D., Ferdiansyah, A., Dharma, H., Hammerstein, O., 2012a. One-dimensional ZnO Nanostructures by Wet-chemistry Technique for Dye Sensitized Solar Cell Application. Advanced Materials Research, Volume 576, pp. 406-412

Yuwono, A.H., Ramahdita, G., Sofyan, N., 2012b. The Nanocrystallinity Enhancement and Optical Characteristics of Pre-hydrothermally Treated ZnO Nanoparticles. Advanced Materials Research, Volume 557-559, pp. 468-471

Zhong, G., Kalam, A., Al-Shihri, A.S., Su, Q., Li, J., Du, G., 2012. Low-temperature Growth of Well-aligned $\mathrm{ZnO}$ Nanorods/Nanowires on Flexible Graphite Sheet and Their Photoluminescence Properties. Materials Research Bulletin, Volume 47(6), pp. 1467-1470 